\title{
Povidone-Iodine Pleurodesis for Chylothorax in an Extremely Low Birth Weight Infant
}

\author{
Jin Woo Kim, $\mathrm{MD}^{1}$, Ju Hyun Jin, $\mathrm{MD}^{2}$, and Shin Won Yoon, $\mathrm{MD}^{2}$ \\ ${ }^{1}$ Department of Pediatrics, Severance Children's Hospital, Yonsei University College of Medicine, Seoul, Korea \\ ${ }^{2}$ Department of Pediatrics, National Health Insurance Service Ilsan Hospital, Goyang, Korea
}

\section{ABSTRACT}

Chylothorax, the accumulation of chyle in the pleural space, is a rare condition, but can lead to serious complications in neonates. Conservative therapy for chylothorax includes enteral feeding with medium-chain triglyceride-enriched diet or parenteral nutrition and administration of octreotide. Surgical management is considered in cases where there is no response to conservative therapy; however, the standardized approach to refractory neonatal chylothorax is still controversial. Chemical pleurodesis can be used when medical therapies for chylothorax fail, to avoid more invasive surgical procedures. We report an extremely preterm infant born at 26 weeks of gestation with refractory chylothorax after patent ductus arteriosus ligation. The infant was successfully treated with pleurodesis using $4 \%$ povidone-iodine, without long-term side effects.

Key Words: Chylothorax; Pleurodesis; Povidone-iodine; Infant, premature

\section{서론}

유미흥(chylothorax)은 흥강 내에 유미(chyle)가 축적되는 상태를 의미하며, 신생아에서는 선 천성 유미흥이 가장 흔한 원인이며, 심혈관계 수술 후 합병증으로 발생하기도 한다. 보고에 따르 면 소아의 선천성 심장질환 수술 후 1.3\%-9.5\%의 빈도로 유미흥이 발생하는 것으로 알려져 있 다 ${ }^{1)}$. 유미흥은 그에 대한 적절한 진단 및 치료가 이루어지지 않을 경우 심각한 호흡기적, 대사적, 면역학적, 영양적인 합병증을 야기할 수 있으며, 이는 생명을 위협하는 문제가 될 수 있다 ${ }^{2)}$. 본 저자들은 초미숙아에서 동맥관개존증 결찰술 후 발생한 유미흥이 보존적 치료에 반응을 보이지 않아 포비돈-요오드(povidone-iodine)를 이용한 흥막유착술(pleurodesis)을 시행하여 성공적으 로 치료한 1예가 있어 보고하는 바이다.

\section{증례}

환아는 재태 연령 26주 1 일, 출생체중 $920 \mathrm{~g}$, 자연분만으로 국민건강보험 일산병원 산부인과
Received: 24 June 2019

Revised: 3 September 2019

Accepted: 2 October 2019

Correspondence to: : Shin Won Yoon, MD

Department of Pediatrics, National Health Insurance Service Ilsan Hospital, 100 Ilsan-ro, Ilsandong-gu, Goyang 10444, Korea

Tel: +82-31-900-0520

Fax: +82-31-900-0343

E-mail: swyoon@nhimc.or.kr

Copyright(c)

By Korean Society of Neonatology.

All right reserved.

This is an Open-Access article distributed under the terms of the Creative Commons Attribution Non-Commercial License (http://creativecommons.org/licenses/ by-nc/4.0), which permits unrestricted non-commercial use, distribution, and reproduction in any medium, provided the original work is properly cited. 
에서 출생한 여아로, Apgar 점수는 1 분에 4 점, 5 분에 5 점이었다. 산 모는 35세로 자궁경부무력증, 조기양막파수, 조기진통이 있었으 며 이외 특이 과거력은 없었다. 환아는 신생아호흡곤란증후군이 있 어 분만실에서 기관 삽관 시행 및 폐계면활성제(Curosurf ${ }^{\circledR}$, Chiesi Farmaceutici SPA, Parma, Italy) 투여하였으며 출생 17시간 후 기 관 삽관 제거하고 비침습적 양압환기를 시행하였다. 출생 5 일째 시 행한 심초음파에서 동맥관개존증이 확인되었으며 수액 제한 및 정 맥 내 ibuprofen 1주기 투여하였으나 혈 역학적으로 의미 있는 증상 이 지속되어 출생 27 일째에 동맥관 결찰술을 시행하였고 흥관(chest tube)을 삽입하였다.

동맥관 결찰술 시행 다음날 좌측 흥강 내에 다량의 흥수가 흥부 방사선 사진(Figure 1A)에서 확인되었으며, 흥관을 통해 배액 된 흥 강액은 옅은 맑은 노란색을 띄었고 검사 상 $\mathrm{pH} 7.0$, 백혈구 8,100/ $\mathrm{mm}^{3}$, 중성구 $81 / \mathrm{mm}^{3}$ (백혈구의 $1 \%$ ), 림프구 $7,452 / \mathrm{mm}^{3}$ (백혈구의 $92 \%$ ), 단핵구 $486 / \mathrm{mm}^{3}$, 중성지방 $127 \mathrm{mg} / \mathrm{dL}$, 콜레스테롤 < $20 \mathrm{mg} /$ $\mathrm{dL}$, 총단백질 2,300 mg/dL, 알부민 $1,700 \mathrm{mg} / \mathrm{dL}$, 당 $75 \mathrm{mg} / \mathrm{dL}, \mathrm{LDH}$ $199 \mathrm{IU} / \mathrm{L}$ 이었다. 세균 배양 검사에서 균은 자라지 않았다. 흉막액 성 분 상 중성지방이 높고 백혈구 중 림프구가 대부분을 차지하여 유미 에 합당한 결과를 보여 동맥관개존증 수술 후 발생한 유미흥으로 진 단하였다. 금식 및 SMOFlipid ${ }^{\circledR}$ (Fresenius Kabi AG)를 포함한 총정 맥영양(total parenteral nutrition, TPN)을 지속하는 보존적 치료를 하였지만 흥수의 양은 줄어들지 않았고 최대 $184.8 \mathrm{~mL} /$ day (130.1 $\mathrm{mL} / \mathrm{kg} /$ day)까지 배액이 되었다(Figure 2). 다량의 흥수 배액이 지속 됨에 따라서 저알부민혈증과 대사성 산증이 발생하였으며, 저나트
륨혈증과 저혈압이 지속되었다. 환자의 혈액 검사 결과에 따라 혈 관 내 용적유지를 위해 신선동결혈장 수혈 및 알부민 주입 등의 치료 를 지속하였으며, 혈압 유지를 위해 승압제가 필요하였다. 보존적인 치료만으로 유미의 양이 감소하지 않는 상태가 지속되어 동맥관 결 찰술 후 9일째에 정맥 내 octreotide 투여를 시작하였다. Octreotide 는 $0.5 \mu \mathrm{g} / \mathrm{kg} / \mathrm{hr}$ 의 용량으로 시작되어 $15 \mu \mathrm{g} / \mathrm{kg} / \mathrm{hr}$ 까지 증량하였 으나 효과가 없었고, octreotide에 대한 부작용으로 괴사성 장염 (necrotizing enterocolitis, $\mathrm{NEC}$ )이 의심되어 동맥관 결찰술 시행 후 19일째에 octreotide 투여를 중단하였다(Figure 1B).

Octreotide 중단 시 흥수 배액양은 $162.6 \mathrm{~mL} /$ day $(116.1 \mathrm{~mL} / \mathrm{kg} /$ day)로 다량의 유미흥이 지속되고 있었다. 그러나 환자의 몸무게가 $1,390 \mathrm{~g}$ 이었으며, 저혈압과 대사성 산증이 반복되어 전신마취를 동 반한 수술적인 치료를 고려할 수 없을 것으로 판단하였고, 동맥관 결 찰술 19일째 포비돈-요오드 흥막유착술을 시행하였다. 흥막유착술 을 시행하기 전 환아의 갑상선자극호르몬은 $0.68 \mathrm{mIU} / \mathrm{L}$ 였으며, 크 레아티닌은 $0.55 \mathrm{mg} / \mathrm{dL}$ 로 정상이었다. $10 \%$ 포비돈-요오드 용액 1.2 $\mathrm{mL}$ 와 생리식염수 $1.8 \mathrm{~mL}$ 를 섞어 $4 \%$ 농도로 희석시킨 포비돈-요오 드 용액을 $5 \mathrm{cc}$ 주사기에 채우고 $22 \mathrm{G}$ 바늘을 사용해 $3 \mathrm{~mL}(2 \mathrm{~mL} / \mathrm{kg})$ 를 흥막천자를 통해 주입하려고 했으나 주입 과정 중 일부가 손실되 어 $1.5 \mathrm{~mL}$ 만 흥강 내로 주입되었다. 첫 번째 흉막유착술 시행 후 흥 수 배액양은 $133.9 \mathrm{~mL} / \mathrm{day}(96.3 \mathrm{~mL} / \mathrm{kg} / \mathrm{day})$ 로 양이 감소하는 것 으로 보아 흥막유착술이 효과가 있다고 판단하였다. 그러나 흥관 의 기능이 원활하지 않아 기흥이 증가하여 다음날 새로운 흥관을 삽 입하면서 전일과 동일하게 희석한 포비돈-요오드 용액 $2 \mathrm{~mL}$ 를 추가
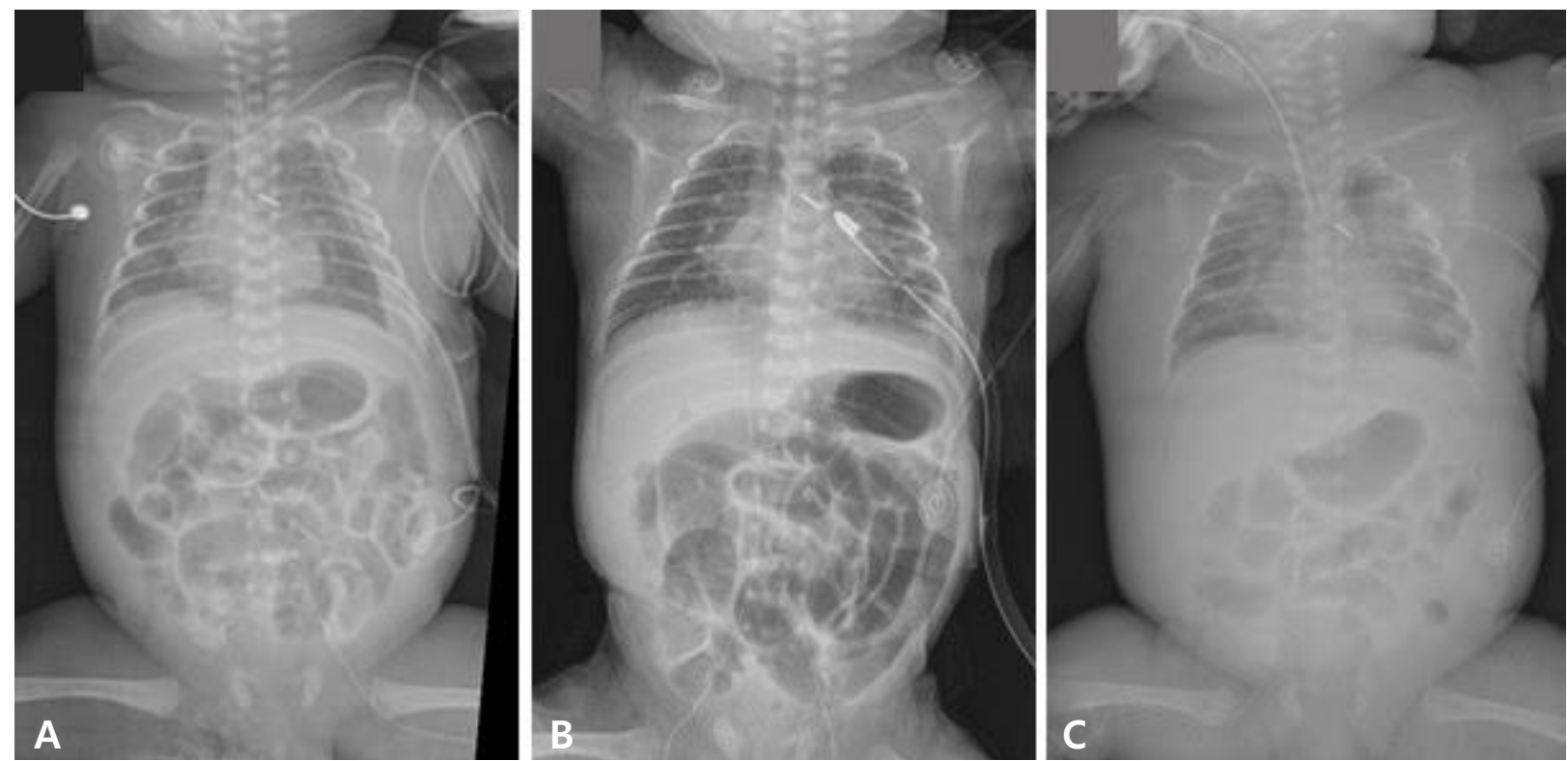

Figure 1. Radiographic findings of the case. (A) On day 1 after patent ductus arteriosus (PDA) ligation, pleural effusion is visualized in the left thoracic cavity. (B) On day 18 after PDA ligation, during octreotide therapy, necrotizing enterocolitis is suspected with notable bowel loop dilatation and ileus. (C) On day 7 of the second povidone-iodine pleurodesis, the chest tube is removed. 


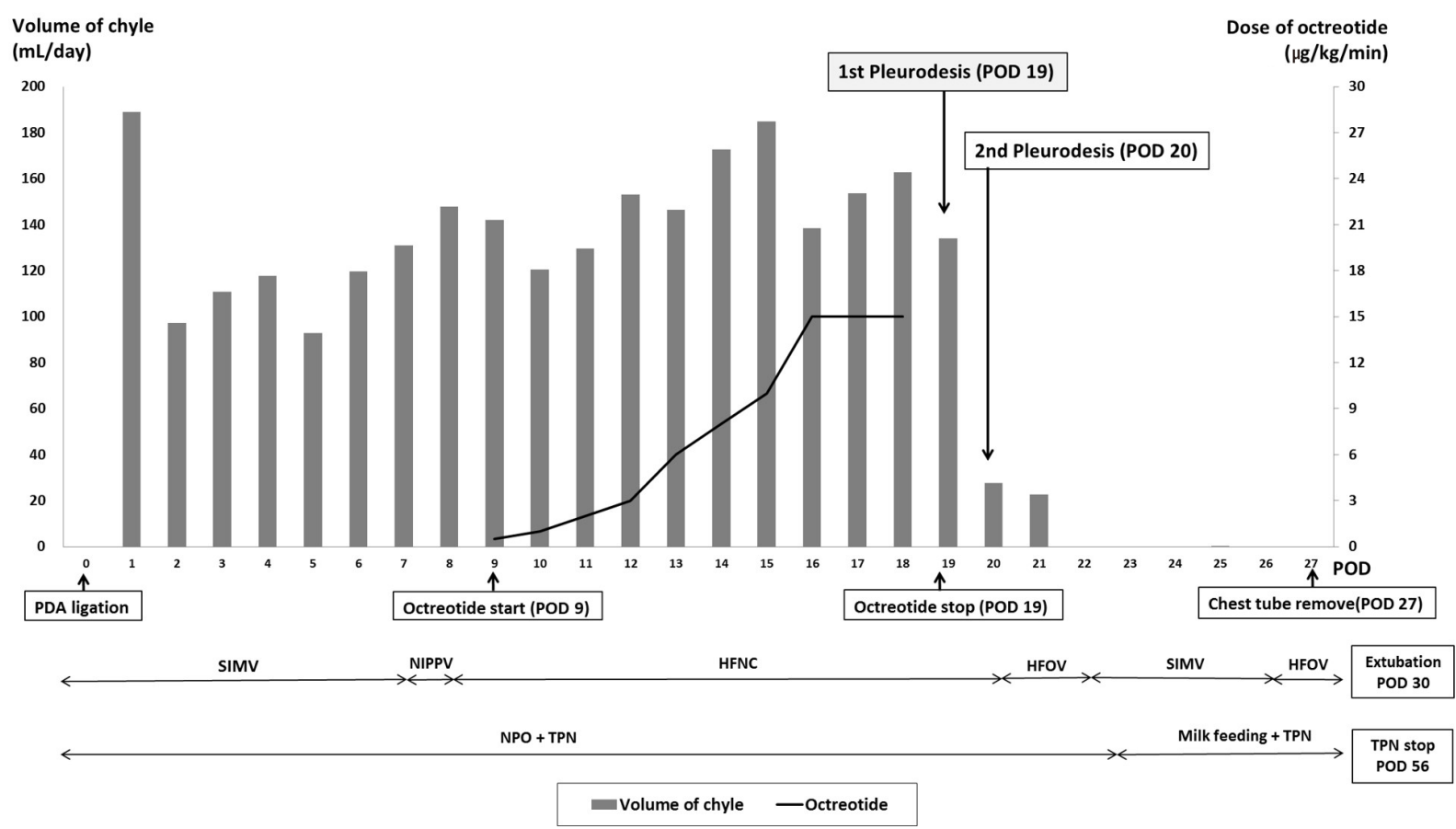

Figure 2. Daily chyle drainage, from the day of patent ductus arteriosus ligation to the day of chest tube removal. Abbreviations: POD, postoperative day; PDA, patent ductus arteriosus; SIMV, synchronized intermittent mandatory ventilation; NIPPV, non-invasive positive pressure ventilation; HFNC, high-flow nasal cannula; HFOV, high frequency oscillatory ventilation; NPO, nil per os; TPN, total parenteral nutrition.

적으로 주입하였다. 주입 당시 혈압은 $50 / 28 \mathrm{~mm} \mathrm{Hg}$, 심박동수 164 회/분, 호흡수 38회/분, 비침습적 양압환기법(non-invasive positive pressure ventilation) $\mathrm{FiO}_{2}$ 0.35에서 산소포화도 94\% 유지되고 있었 으며 주입 직후 활력징후의 차이는 보이지 않았다. 투여 5시간째 정 맥혈 가스 검사상 이산화탄소가 저류되어 기관 삽관 및 고빈도 진동 환기요법 치료가 필요하였다. 두 번째 흥막유착술 시행일 이후부터 흥수 배액양은 $27.7 \mathrm{~mL} / \mathrm{day}(19.5 \mathrm{~mL} / \mathrm{kg} / \mathrm{day})$ 로 현저히 감소하였 고, 3 일째부터는 모유수유를 시작하였으나 흥수가 배액되지 않았으 며 7일째에는 흥관을 제거할 수 있었다(Figures 1C, 2). 기관 삽관은 두 번째 흉막유착술 시행 10 일째에 발관하였다.

두 번째 흥막유착술 시행 당일 소변량이 $0.5 \mathrm{~mL} / \mathrm{kg} / \mathrm{day}$ 로 감소하 였으나 다음날부터 $1 \mathrm{~mL} / \mathrm{kg} / \mathrm{day}$ 이상 유지되었다. 혈중 크레아티닌 농도는 점차 증가하여 두 번째 흥막유착술 시행 10 일째 $2.72 \mathrm{mg} / \mathrm{dL}$ 까지 상승하였으나 시술 18 일째에는 $0.66 \mathrm{mg} / \mathrm{dL}$ 로 회복되었다. 흥 막유착술 시행 9일째 시행한 복부 초음파검사상 미만성 신질환을 시 사하는 양측성 신실질 초음파 음영 증가 소견이 관찰되었다. 갑상선 자극호르몬은 흥막유착술 시행 24일째 $7.29 \mathrm{mIU} / \mathrm{L}$ 로 약간 증가하 였으나, 41 일째에는 $3.29 \mathrm{mIU} / \mathrm{L}$ 로 정상화되었다. 유리 티록신(free $\mathrm{T} 4)$ 과 삼요오드티로닌(T3)도 각각 $1.70 \mathrm{ng} / \mathrm{dL}, 108 \mathrm{ng} / \mathrm{dL}$ 로 정상이 었다.

환아는 생후 5 개월(교정연령 47 주)에 $4.49 \mathrm{~kg}$ 의 체중으로 신생아
집중치료실에서 가정으로 퇴원하였다. 퇴원 시에는 기관지 폐이형 성증으로 인하여 수유 시에만 보조적인 간헐적 산소치료를 필요로 하였다. 미숙아 망막증 소견은 보이지 않았고, 퇴원 시 혈중 크레아 티닌 농도는 $0.21 \mathrm{mg} / \mathrm{dL}$ 였다. 교정연령 8 개월에 외래 추적 시 시행 한 복부 초음파에서도 양측성 미만성 신질환 외에 특이 소견은 보이 지 않았고 신기능은 정상이었다. 교정연령 20개월에 신기능 검사 및 복부초음파를 추적검사 예정이다. 현재 환아는 21개월(교정연령 17 개월)이며 산소 요구량 없이 생활 중이고 독립 보행이 가능하나 발 달지연으로 인해 재활치료 중이다.

\section{고찰}

신생아의 유미흥은 소아에서 유병률이 5,775-24,000명 중 1명으 로 매우 드문 질환이지만 신생아기 흥막삼출의 가장 흔한 원인이며, 사망률이 64\%에 이를 수 있는 심각한 질환이 될 수 있다 ${ }^{3)}$. 유미는 맑 고 노란색을 띠며 경구 영양을 한 후에는 우윳빛으로 변하게 되는 데 다량의 단백질, 지방, 림프구를 포함한다. 유미흥은 흥수의 중성 지방이 $110 \mathrm{mg} / \mathrm{dL}$ 이상이고 콜레스테롤이 혈장보다 낮아 혈장과의 비율이 1.0 미만이며 백혈구가 $1,000 / \mathrm{mL}$ 이상이고 그 중 림프구가 $80 \%$ 이상일 때 진단할 수 있다. 또한 지단백 전기영동을 이용하여 
유미지립의 존재를 확인하여 확진할 수 있다. 가성유미는 감염이나 흥막 내 종양에 의하여 만성적으로 발생하며 혼탁하고 우윳빛을 띄 며 림프구가 적고 중성지방이 낮고 콜레스테롤이 높아 혈장과의 비 율이 1.0 이상으로 나타난다 ${ }^{2}$. 유미흥이 지속되면 흥수를 통해서 림 프구, 단백질, 면역글로불린, 전해질, 지방 등이 소실되어 감염에 취 약하게 되며, 영양의 불균형을 가져온다. 또한 치료 과정에서 금식, 기관 삽관, 흥관과 중심정맥관 거치의 장기화 등으로 인해 합병증 발 생의 가능성이 더 높아지게 된다.

유미흉에 대한 보존적 치료 방법으로는 흥관 삽입술을 시행하여 배액하고 림프관을 통하지 않고 직접 문맥으로 흡수되는 중쇄 중성 지방(medium-chain triglyceride) 분유 수유나 금식과 총 정맥영양을 우선적으로 시도해볼 수 있다. 다음 단계의 치료로는 복부 내장으로 의 혈류를 감소시키는 somatostatin 또는 octreotide를 투여할 수 있 다, ${ }^{2,45}$. Somatostatin과 octreotide의 투여는 비교적 안전하지만, 포 도당 불내증, 갑상선기능 저하증, 경련, 구역감, 설사, 신기능 저하, $\mathrm{NEC}$, 간기능 장애, 아나필락시스가 부작용으로 발생할 수 있다 ${ }^{4,5)}$. 본 환아에서는 octreotide를 10 일 동안 최대 용량인 $15 \mu \mathrm{g} / \mathrm{kg} / \mathrm{hr}$ 까 지 높여 사용하였음에도 반응이 없었으며, 장내 혈류를 감소시키는 부작용으로 인해 복부 팽만과 복부 X-ray 에서 장폐색 소견을 보여 NEC 의심 하에 중단을 하였다. Octreotide 치료는 70\%에서 효과적 인 것으로 보고되고 있으나 적절한 용량과 사용기간에 대한 치료방 침은 정립되어 있지 않다).

이와 같은 내과적 치료를 통한 유미의 양의 감소와 흥관(thoracic duct)의 치유가 실패했을 경우에는 수술적 치료를 고려해야 한다. 유미흥에 대한 수술적 치료로 직접적인 흥관결찰술을 시행할 수 있 으며, 그 외에 흥복막 우회술, 투시검사 유도하 경피적 복벽 경유 흥 관 색전술이 있달. 유미흥이 있는 경우 흉관결찰술을 시행하는 적 응증은 아직 확실히 정립되어 있지 않으나, 보존적 치료에도 불구하 고 3-4주간 배액이 지속되거나 배액 양이 $10 \mathrm{~mL} / \mathrm{kg} /$ day 이상일 때 수술적 치료가 고려된다 ${ }^{2,(6)}$. 또한 흉관결찰술을 하여도 유미흥이 줄 어들지 않거나 재발하는 경우도 있어 수술을 결정함에 있어 유미액 의 양과 기간 외에도 많은 고려가 필요할 것으로 생각된다. 특히 침 습적인 수술적 치료를 시행하기 어려운 영아에서는 약물을 사용하 는 흥막유착술이 대안이 될 수 있다.

흥막유착술은 약물을 이용하여 흥막 사이의 유착을 유발하여 림프액이나 유미의 유출을 막는 방법으로, 테트라사이클린(tetracycline), 활석(talc), 블레오마이신(bleomycin), 섬유소 접착제(fibrin glue), 포비돈-요오드, OK-432 (picibanil) 등이 사용될 수 있다2). 신 생아에서는 viscum album, oxytetracycline, OK-432 그리고 포비 돈-요오드를 사용한 소수의 증례보고들이 있다 ${ }^{7-9)}$. 포비돈-요오드 가 흥막을 유착시키는 기전은 불분명하지만 경화용액(sclerosing solution)의 낮은 $\mathrm{pH}$ ( $\mathrm{pH}$ 2.97)와 요오드의 강한 산화력 및 세포독성 으로 인해 염증반응을 유발하여 작용하는 것으로 보인다 ${ }^{10)}$.
포비돈-요오드 흥막유착술은 주로 성인의 악성흥수 치료에서 비 교적 안전하고 효과적인 치료로 사용되고 있으나, $10 \%$ 포비돈-요오 드 용액을 사용하는 경우에 이 용액에 포함되어 있는 요오드산염이 망막색소상피를 파괴시켜 시력이 상실된 성인 증례보고도 있었다 ${ }^{11)}$. 그러나 $4 \%$ 의 농도에서는 요오드산염의 중독량인 체중당 $10 \mathrm{mg}$ 의 농 도에 못 미치게 되며 신생아에서 망막증이 보고된 예는 없었다. 그 외의 포비돈-요오드 흉막유착술의 주요 부작용으로는 흥통, 저혈압, 알레르기 반응, 갑상선 중독증이 보고되고 있어 시술 전후 갑상선기 능검사를 시행하고 활력징후에 대한 모니터링이 필요하다 ${ }^{12)}$.

신생아에서의 포비돈-요오드를 사용한 흥막유착술을 보고한 이 전 연구들을 ${ }^{6,10,13-20)}$ 살펴보면 본 연구를 포함하여 총 20예가 보고되 었는데(Table 1), 진단명은 대부분 선천성 유미흥이었으며 수술 후 발생한 유미흥은 5 예 있었다 ${ }^{17}$. 출생체중 $1,000 \mathrm{~g}$ 미만의 초극소 저 체중출생 미숙아는 본 연구를 포함하여 3 예가 보고되었는데 ${ }^{15,17)}$, 그 중 1예는 기흥에서 포비돈-요오드 흥막유착술을 시행한 것이고, 2 예 는 유미흥에서 사용하였다. 총 20 명 중 15 명(75\%)이 치료에 성공하 여 유미흥이 호전되어 흥관 제거가 가능하였다. 유미흥 치료에 성공 한 15명 중 13명(65\%)은 장기적인 합병증이 발생하지 않았으며, 1 명 은 만성신부전이 발생하였고 나머지 1명은 유미흥 치료에는 성공하 였으나 다발 장기 손상으로 인해 사망하였다. 사망한 것으로 보고된 4 명 중 2명은 28주와 29주 출생의 미숙아로 다발성 장기 부전에 인 한 사망이었으며, 1 명은 칸디다 감염에 의한 신부전, 1 명은 수술에 의한 합병증으로 사망한 것으로 보고되었다 ${ }^{10,14)}$.

급성신부전의 합병증은 본 증례를 포함한 3명에서 보고되었다. Brissaud 등 $^{10}$ 이 보고한 4 번 증례 환아는 말기신부전으로 사망하였 으나 시술 이전에 칸디다에 의한 신정맥혈전증이 있었고 포비돈-요 오드가 신부전을 악화시킨 것으로 보았다. 또한 미만성 림프관확장 증(diffuse lymphangiectasia) 의 경우로 요오드 흡수가 증가되었다 고 보여지며, $4 \%$ 용액을 사용하였으나 3 회의 용량으로 투여한 경 우로 비교적 고용량이 투여되어 신독성이 증가한 것으로 보인다. Mitanchez 등 ${ }^{13)}$ 이 보고한 5 번 증례에서는 고농도 $10 \%$ 용액을 사용 한 경우로 시술 후 발생한 급성신부전이 만성신부전으로 지속되었 다. 본 증례에서도 시술 후 급성신부전이 발생하였는데 26주의 초미 숙아에서의 사용으로 신독성이 증가할 수 있을 것으로 생각된다.

따라서 고농도와 고용량 포비돈-요오드 투여가 흥막유착술의 합 병증으로 신부전이 발생하는데 연관성이 있을 것으로 보이며, 신생 아에서 포비돈-요오드 흥막유착술을 시행할 경우에는 고농도와 고 용량 투여를 지양해야 할 것이다. 또한 미숙아에서 시술 시에는 신 기능에 대한 많은 주의가 필요할 것으로 사료된다.

20 명 중 갑상선 기능 이상을 보인 경우는 없었고 일시적인 호흡곤 란 증상이 7명에서 보고되었다 ${ }^{13,14,17)}$. 포비돈-요오드가 흥막에 염증 반응을 유발하게 되므로 폐허탈을 일으켜 일시적인 호흡곤란 증상 을 일으킬 수 있는 것으로 되어 있으나 장기적인 폐기능의 장애는 일 
Table 1. Povidone-Iodine Pleurodesis in Newborn Infants

\begin{tabular}{|c|c|c|c|c|c|c|c|c|c|c|c|}
\hline Study & Year & Case & $\begin{array}{l}\text { Gesta- } \\
\text { tional } \\
\text { age } \\
\text { (wk) }\end{array}$ & $\begin{array}{l}\text { Birth } \\
\text { weight } \\
\text { (g) }\end{array}$ & $\begin{array}{l}\text { Age at } \\
\text { procedure } \\
\text { (d) }\end{array}$ & $\begin{array}{l}\text { Diagnosis/ } \\
\text { Site }\end{array}$ & $\begin{array}{l}\text { Povidone- } \\
\text { iodine } \\
\text { solution } \\
(\%)\end{array}$ & $\begin{array}{l}\text { Povidone- } \\
\text { iodine } \\
\text { dose } \\
(\mathrm{mL})\end{array}$ & $\begin{array}{l}\text { Result/ } \\
\text { chest } \\
\text { tube } \\
\text { removal } \\
\text { (d) }\end{array}$ & Adverse effects & Outcome \\
\hline \multirow[t]{3}{*}{$\begin{array}{l}\text { Brissaud } \\
\text { et al. }^{10)}\end{array}$} & \multirow[t]{3}{*}{2003} & 1 & 31 & NA & 65 & $\begin{array}{l}\text { CIC } \\
\text { Right }\end{array}$ & 4 & 10 & $\begin{array}{c}\text { Success } \\
16\end{array}$ & None & Survival \\
\hline & & 3 & 36 & NA & 59 & $\begin{array}{l}\text { CIC } \\
\text { Right }\end{array}$ & 10 & 3 & $\begin{array}{c}\text { Success } \\
6\end{array}$ & Generalized edema & Survival \\
\hline & & 4 & 36 & NA & $\begin{array}{l}\text { Left 22, } 26 \\
\text { Right } 25\end{array}$ & $\begin{array}{l}\text { Diffuse lymphan- } \\
\text { giectasis } \\
\text { Bilateral }\end{array}$ & 4 & 5 & Failure & $\begin{array}{l}\text { Renal failure, } \\
\text { Bilateral candida } \\
\text { related thrombosis of } \\
\text { the renal vein }\end{array}$ & $\begin{array}{l}\text { Death } \\
\text { End stage renal } \\
\text { failure, oliguria, } \\
\text { hydrops, hypo- } \\
\text { tension }\end{array}$ \\
\hline Murki et al. ${ }^{6)}$ & 2010 & 6 & Term & 3,880 & 30,32 & $\begin{array}{l}\text { CIC } \\
\text { Bilateral }\end{array}$ & $\begin{array}{c}10 \\
\text { Diluted to } \\
4 \text { with NS }\end{array}$ & & $\begin{array}{c}\text { Success } \\
\text { NA }\end{array}$ & None & Survival \\
\hline \multirow[t]{2}{*}{$\begin{array}{l}\text { Le Nue et } \\
\text { al. }^{14)}\end{array}$} & \multirow[t]{2}{*}{2010} & 7 & $35^{+4}$ & 2,400 & NA & $\begin{array}{l}\text { CIC } \\
\text { Bilateral }\end{array}$ & NA & NA & $\begin{array}{l}\text { Failure } \\
\text { NA }\end{array}$ & None & Survival \\
\hline & & 8 & $35^{+3}$ & 2,636 & NA & $\begin{array}{l}\text { CIC } \\
\text { Right }\end{array}$ & NA & NA & $\begin{array}{c}\text { Failure } \\
\text { NA }\end{array}$ & Respiratory distress & Survival \\
\hline \multirow[t]{5}{*}{$\begin{array}{l}\text { Scottoni et } \\
\text { al. }^{17)}\end{array}$} & \multirow[t]{5}{*}{2015} & 12 & 40 & 2,650 & 67 & $\begin{array}{l}\text { CIC } \\
\text { Bilateral }\end{array}$ & 4 & $2 \mathrm{~mL} / \mathrm{kg}$ & $\begin{array}{l}\text { Success } \\
\text { NA }\end{array}$ & $\begin{array}{l}\text { Lung atelectasis/acute } \\
\text { respiratory distress in } \\
\text { three patients }\end{array}$ & Survival \\
\hline & & 13 & 35 & 2,830 & 34 & $\begin{array}{l}\text { Acquired after sur- } \\
\text { gery of type C EA } \\
\text { Right }\end{array}$ & 4 & $2 \mathrm{~mL} / \mathrm{kg}$ & $\begin{array}{c}\text { Success } \\
\text { NA }\end{array}$ & & Survival \\
\hline & & 14 & 41 & 3,670 & 34 & $\begin{array}{l}\text { Acquired after car- } \\
\text { diac surgery } \\
\text { Left }\end{array}$ & 4 & $2 \mathrm{~mL} / \mathrm{kg}$ & $\begin{array}{c}\text { Success } \\
\text { NA }\end{array}$ & & Survival \\
\hline & & 15 & 28 & 672 & $\begin{array}{l}\text { Right } 36 \\
\text { Left } 42\end{array}$ & $\begin{array}{l}\text { Acquired after } \\
\text { surgery of SVC } \\
\text { thrombosis } \\
\text { Bilateral }\end{array}$ & 4 & $2 \mathrm{~mL} / \mathrm{kg}$ & Failure & & $\begin{array}{l}\text { Death } \\
\text { Multiple organ } \\
\text { failure }\end{array}$ \\
\hline & & 16 & 39 & 2,970 & 27 & $\begin{array}{l}\text { cquired after car- } \\
\text { diac surgery } \\
\text { Left }\end{array}$ & 4 & $2 \mathrm{~mL} / \mathrm{kg}$ & $\begin{array}{c}\text { Success } \\
\text { NA }\end{array}$ & & Survival \\
\hline
\end{tabular}


Table 1. Continued

\begin{tabular}{|c|c|c|c|c|c|c|c|c|c|c|c|}
\hline Study & Year & Case & $\begin{array}{l}\text { Gesta- } \\
\text { tional } \\
\text { age } \\
\text { (wk) }\end{array}$ & $\begin{array}{l}\text { Birth } \\
\text { weight } \\
\text { (g) }\end{array}$ & $\begin{array}{c}\text { Age at } \\
\text { procedure } \\
\text { (d) }\end{array}$ & $\begin{array}{l}\text { Diagnosis/ } \\
\text { Site }\end{array}$ & $\begin{array}{l}\text { Povidone- } \\
\text { iodine } \\
\text { solution } \\
(\%)\end{array}$ & $\begin{array}{l}\text { Povidone- } \\
\text { iodine } \\
\text { dose } \\
(\mathrm{mL})\end{array}$ & $\begin{array}{l}\text { Result/ } \\
\text { chest } \\
\text { tube } \\
\text { removal } \\
\text { (d) }\end{array}$ & Adverse effects & Outcome \\
\hline $\begin{array}{l}\text { Resch et } \\
\text { al. }^{18)}\end{array}$ & 2016 & 17 & 29 & 1,530 & 35 & $\begin{array}{l}\text { Congenital } \\
\text { pulmonary } \\
\text { lymphangiectsia } \\
\text { Bilateral }\end{array}$ & 10 & 4.8 & $\begin{array}{c}\text { Success } \\
2\end{array}$ & NA & $\begin{array}{l}\text { Death } \\
\text { Multiple organ } \\
\text { failure }\end{array}$ \\
\hline $\begin{array}{l}\text { Kasdallah et } \\
\text { al. }^{19)}\end{array}$ & 2016 & 18 & 39 & 3,050 & 15 & $\begin{array}{l}\text { CIC } \\
\text { Right }\end{array}$ & 4 & 5 & $\begin{array}{c}\text { Success } \\
2\end{array}$ & None & Survival \\
\hline $\begin{array}{l}\text { Borcyk et } \\
\text { al. }^{20)}\end{array}$ & 2018 & 19 & 33 & 2,165 & 30 & $\begin{array}{l}\text { CIC } \\
\text { Bilateral }\end{array}$ & 4 & 6 & $\begin{array}{c}\text { Success } \\
11\end{array}$ & None & Survival \\
\hline $\begin{array}{r}\text { Present } \\
\text { study }\end{array}$ & 2019 & 20 & $26+1$ & 920 & Left 46, 47 & $\begin{array}{l}\text { Acquired after } \\
\text { cardiac surgery } \\
\text { Left }\end{array}$ & $\begin{array}{c}10 \\
\text { Diluted to } \\
4 \text { with NS }\end{array}$ & $1.5,2$ & $\begin{array}{c}\text { Success } \\
7\end{array}$ & Acute renal failure & Survival \\
\hline
\end{tabular}

Abbreviations: NA, not available; CIC, congenital idiopathic chylothorax; NS, normal saline; EA, esophageal atresia; SVC, superior vena cava.

으키지 않는 것으로 나타났다. 본 증례에서도 시술 후에 충분한 환 기가 되지 않아 호흡기 치료가 필요하였으나 무기폐 소견은 보이지 않았고 점차 호전되어 수일 후에는 호흡기 이탈이 가능하였다. 포비 돈-요오드 투여 시에는 급성호흡곤란에 대한 주의와 호흡 보조 요법 에 대한 대비가 필요할 것으로 사료된다.

포비돈-요오드 흥막유착술은 유미흥 치료의 선택이 될 수 있지만, 보고된 바와 같이 합병증이 발생 가능하므로 Octreotide에 듣지 않 는 불응성 유미흥에서 신기능 장애가 없고 갑상선 기능 검사가 정상 인 경우에 시도해 볼 수 있으며 흥막유착술 시행 전후로 갑상선기능 검사뿐만 아니라 신기능 검사와 호흡 상태에 대한 주의 깊은 모니터 링이 필요하다. 또한 선천성 림프관확장증과 같이 요오드 흡수가 증 가될 수 있는 경우와 신독성이 증가할 수 있는 미숙아의 경우에서는 보다 주의 깊은 투여가 필요하겠다.

아직까지 신생아에서는 불응성 유미흥의 치료에 대한 보고가 매 우 적은 상태로 2010 Cochrane review에서는 신생아의 불응성 유미 흥 치료에 대한 대조 시험(controlled trial)이 부족하여 치료 지침에 대한 결론을 내지 못한 상태이다 ${ }^{5}$. 포비돈-요오드 및 약물을 사용한 흥막유착술에 대한 소수의 보고만으로는 치료방침이 분명하지 않은 바, 본 사례는 국내에서 처음으로 보고하는 초극소 저체중출생 미숙 아에서 수술 후에 발생한 유미흥을 포비돈-요오드 흥막유착술을 통 해 성공적으로 치료한 증례로서, 포비돈-요오드 흥막유착술이 보존 적인 치료에 실패하고 침습적인 수술이 어려운 신생아의 유미흥 치 료의 선택지가 될 수 있을 것으로 사료된다.

\section{ARTICLE INFORMATION}

\section{Ethical statement}

This study was approved by the Institutional Review Board of National Health Insurance Service Ilsan Hospital (IRB No. NHIMC 2019-05-009). Informed consent was waived by the board.

\section{Conflicts of interest}

No potential conflict of interest relevant to this article was reported.

\section{Author contributions}

Conception or design: J.W.K., J.H.J., S.W.Y.

Acquisition, analysis, or interpretation of data: J.W.K., J.H.J., S.W.Y.

Drafting the work or revising: J.W.K., J.H.J., S.W.Y.

Final approval of the manuscript: J.W.K., J.H.J., S.W.Y.

\section{ORCID}

Jin Woo Kim https://orcid.org/0000-0001-7908-9498

Shin Won Yoon https://orcid.org/0000-0001-7582-6251

\section{Acknowledgments}

None 


\section{REFERENCES}

1. Matsuo S, Takahashi G, Konishi A, Sai S. Management of refrac tory chylothorax after pediatric cardiovascular surgery. Pediatr Cardiol 2013;34:1094-9.

2. Tutor JD. Chylothorax in infants and children. Pediatrics 2014; 133:722-33.

3. Bialkowski A, Poets CF, Franz AR; Erhebungseinheit fur seltene padiatrische Erkrankungen in Deutschland Study Group. Congenital chylothorax: a prospective nationwide epidemiolo gical study in Germany. Arch Dis Child Fetal Neonatal Ed 2015; 100:F169-72.

4. Roehr CC, Jung A, Proquitte H, Blankenstein O, Hammer H, Lakhoo K, et al. Somatostatin or octreotide as treatment options for chylothorax in young children: a systematic review. Intensive Care Med 2006;32:650-7.

5. Das A, Shah PS. Octreotide for the treatment of chylothorax in neonates. Cochrane Database Syst Rev 2010;9:CD006388.

6. Murki S, Faheemuddin M, Gaddam P. Congenital chylothorax: successful management with chemical pleurodesis. Indian J Pediatr 2010;77:332-4.

7. Cho HJ, Na KJ, Kim DW, Choi YE, Ma JS, Jeong IS. Chemical pleurodesis using a Viscum album extract in infants with congenital chylothorax. Eur J Pediatr 2014;173:823-6.

8. Utture A, Kodur V, Mondkar J. Chemical pleurodesis with oxytetracycline in congenital chylothorax. Indian Pediatr 2016; 53:1105-6.

9. Kim JE, Lee C, Park KI, Park MS, Namgung R, Park IK. Successful pleurodesis with OK-432 in preterm infants with persistent pleural effusion. Korean J Pediatr 2012;55:177-80.

10. Brissaud O, Desfrere L, Mohsen R, Fayon M, Demarquez JL. Congenital idiopathic chylothorax in neonates: chemical pleurodesis with povidone-iodine (Betadine). Arch Dis Child Fetal Neonatal Ed 2003;88:F531-3.
11. Wagenfeld L, Zeitz O, Richard G. Visual loss after povidoneiodine pleurodesis. N Engl J Med 2007;357:1264-5.

12. Agarwal R, Aggarwal AN, Gupta D. Efficacy and safety of iodopovidone pleurodesis through tube thoracostomy. Respirology 2006;11:105-8.

13. Mitanchez D, Walter-Nicolet E, Salomon R, Bavoux F, Hubert P. Congenital chylothorax: what is the best strategy? Arch Dis Child Fetal Neonatal Ed 2006;91:F153-4.

14. Le Nue R, Molinaro F, Gomes-Ferreira C, Scheib-Brolly C, Escande B, Kuhn P, et al. Surgical management of congenital chylothorax in children. Eur J Pediatr Surg 2010;20:307-11.

15. Arayici S, Simsek GK, Oncel MY, Yilmaz Y, Canpolat FE, Dilmen U. Povidone-iodine for persistent air leak in an extremely low birth weight infant. J Pediatr Surg 2013;48:E21-3.

16. Hmami F, Oulmaati A, Bouchikhi C, Banani A, Bouharrou A. Congenital chylothorax: rapid and complete response to polyvidone iodine. Arch Pediatr 2014;21:1002-5.

17. Scottoni F, Fusaro F, Conforti A, Morini F, Bagolan P. Pleurodesis with povidone-iodine for refractory chylothorax in newborns: personal experience and literature review. J Pediatr Surg 2015; 50:1722-5.

18. Resch B, Freidl T, Reiterer F. Povidone-iodine pleurodesis for congenital chylothorax of the newborn. Arch Dis Child Fetal Neonatal Ed 2016;101:F87-8.

19. Kasdallah N, Kbaier H, Ben Salem H, Blibech S, Bouziri A, Douagi M. Povidone iodine pleurodesis for refractory congenital chylothorax: a review of literature. Tunis Med 2016;94:834.

20. Borcyk K, Kamil A, Hagerty K, Deer M, Tomich P, Anderson Berry AL. Successful management of extremely high-output refractory congenital chylothorax with chemical pleurodesis using $4 \%$ povidone-iodine and propranolol: a case report. Clin Case Rep 2018;6:702-8. 